\title{
The Role Of Nurses In Providing Social Support In Tuberculosis Treatment: Literature Review
}

\author{
Ni Nyoman Elfiyunai ${ }^{1}$, Moses Glorino Rumambo Pandin ${ }^{2}$ \\ ${ }^{1}$ Program Doktor Nursing Faculty Universitas Airlangga Surabaya \\ ${ }^{2}$ Department of English Literature, Faculty of Humanities, Universitas Airlangga \\ Corespoden Author : \\ Ni Nyoman Elfiyunai \\ Email : ni.nyoman.elfiyunai-2020@fkp.unair.ac.id
}

\begin{abstract}
Background Tuberculosis is a type of infectious disease that can cause death if treatment is not completed. the duration of tuberculosis treatment can reach 6 to 8 months so it really requires discipline when doing treatment. This makes tuberculosis patients in dire need of health information and social support which is very helpful in providing motivation, health information, and monitoring treatment from nurses. Aim of this literature review is to provide an overview of the The Role Of Nurses In Providing Social Support In Tuberculosis Treatment: Literature Review. Method is a literature review research, this study uses electronic database searches using keywords according to research questions from the online library PubMed, Content Science, and Science Direct. Result it was found that the role of nurses in the aspect of social support, namely in providing motivation, supervision, comfort, empathy, and information. this is very necessary for patients with tuberculosis at the time of treatment. Conclution social support is needed by tuberculosis patients who are currently undergoing treatment to provide motivation, health information, and as a nurse's supervision of patient adherence to tuberculosis treatment.
\end{abstract}

Keyword: Social Suppport, Tuberculosis, Nursing, Information Support

\section{INTRODUCTION}

Tuberculosis is a contagious disease caused by pulmonary tuberculosis (Mycobacterium tubercolusis) (Organization, 2019). In addition, Tuberculosis is also caused by environmental and food factors, which cannot be completely cured if Tuberculosis patients do not undergo routine treatment. Which routine treatment can be a challenge in itself. This is due to the non-stop treatment which lasts 6 to 8 months (Christof et al., 2020). The continuous treatment process will have a psychological impact on Tuberculosis patients such as feeling boredom and tired in undergoing the treatment process (Baniqued et al., 2020; Nezenega et al., 2020).

Perceptual aspects of social support are emotional support, appraisal support, information support, and instrumental support. Social support from health workers and nursing is needed by TB patients because this social support can create a feeling of 
security, attention, comfort because they feel that there are other individuals who support, accept their existence, and do not isolate them. In addition, the positive perceptions that arise from this social support can also help eliminate negative attitudes of Tuberculosis patients such as eliminating feelings of inferiority (Baniqued et al., 2020; Nezenega et al., 2020; Watermeyer and Penn, 2019).

Aspects of social support are emotional support, appraisal support, information support, and instrumental support. Social support from health workers and nursing is needed by TB patients because this social support can create a feeling of security, attention, comfort because they feel that there are other individuals who support, accept their existence, and do not isolate them. In addition, the positive perceptions that arise from this social support can also help eliminate negative attitudes of Tuberculosis patients such as eliminating feelings of inferiority (Ainiyah et al., 2019; Browne et al., 2019).

In this $21^{\text {st }}$ century technology is no longer an extraordinary thing but a necessity. Where technology can provide many benefits for everyday life (Cox et al., 2019; Sekandi et al., 2021). One form of technology that is often used in this century is the smartphone which is one of the electronic media apart from being a communication tool as well as a source of information, knowledge, and as a document storage medium. In the world of health, smartphones also take part in providing health information and as reminders of treatment (Cox et al., 2019; Kumar et al., 2019).

\section{METHODS}

This research is a literature review research. In searching for journals in this literature review, using the online library to search for journals relevant to the theme The Role Of Nurses In Providing Social Support In Tuberculosis Treatment: Literature Review in this literature, namely PubMed, Content Sciendo, and Science Direct. Search for related articles based on the keyword in the research question. Keyword: "Social Suppport”, AND “Tuberculosis", AND "Nursing”, OR "Information Support”.

\section{Inclusion criteria}

The literature used in writing this journal is literature that meets the inclusion criteria. The inclusion criteria in this journal are determined based on: topics about the role of nurses in providing social support for tuberculosis published in 2019 to 2021, full text directed in english language, and using qualitative research design and quantitative designed as a quantitative and qualitative research.

\section{RESULT}

Article searches that have been carried out by filtering according to research keywords in the last 3 years obtained 129 articles related to tuberculosis. Then the articles related to the questions in this study were filtered again so that they became 8 related journals. Based on 8 journals, it was found that the role of nurses in the aspect of social support, namely in providing motivation, supervision, comfort, empathy, and information. this is very necessary for patients with tuberculosis at the time of treatment.

Review journals from 8 journals related to the theme of social support, and tuberculosis according to the inclusion criteria, with the following results: 
Table 1. review journal

\begin{tabular}{|c|c|}
\hline Research & Methods \\
\hline $\begin{array}{l}\text { (Baniqued et al., 2020) } \\
\text { "Social support from } \\
\text { nurses and non- } \\
\text { adherence with directly } \\
\text { observed therapy } \\
\text { (DOTS) maintenance } \\
\text { phase among patients } \\
\text { with tuberculosis" }\end{array}$ & $\begin{array}{l}\text { Design: Prospective- } \\
\text { cohort. } \\
\text { Sample: } 100 \text { Participant } \\
\text { Analysis: Cox } \\
\text { proportional-hazards } \\
\text { regression }\end{array}$ \\
\hline
\end{tabular}

(Arifin et al., 2019)

"The Relationship of Social Support with Medication Adherence Pulmonary Tuberculosis Patients Through DOTS Strategy in Pidie Aceh Indonesia"
Design: cross sectional Sample: 80 Participant Analysis: Chi-Square Test and logistic regression test with $\alpha=$ 0,05

\section{Nurse role in sosial support}

Social support provided by nurses can influence DOTS nonadherence in TB patients, a health issue in the development of drug resistance. Emotional perceptions, instrumental, seeking support, and receiving emotional support reduce the danger of nonadherence, while receiving emotional support increases nonadherence.

One of the social support provided by nurses is in the form of emotional support which includes expressions of empathy, care, and attention given by nurses as treatment supervisors for TB patients. For example, a nurse feels the suffering of TB patients (in this case the nurse feels empathy). This support will make tuberculosis patients who are undergoing treatment feel comfortable, feel owned and loved when under stress, calm down, personal warmth, provide encouragement, and love.

Nurses play an important role for the success of Tuberculosis

(Carlsson et al., 2019)

"Nurses' Roles and

Experiences with

Enhancing Adherence to

Tuberculosis Treatment among Patients in Burundi”
Design: descriptive design

Sample: 8 nurse participant Analysis: Content analysis treatment. in this case the nurse plays a role in giving Educating patients, administering medication, communicating with patients, observing and following up on treatment on an ongoing basis are the nurses' primary duties to support adherence.

(Sukartini et al., 2019)

"Knowledge, Family

And Social Support, Self Efficacy And Self-Care Behaviour In Pulmonary

Design: cross sectional Sample: 65 respondents Analysis: Spearman's Tuberculosis Patients"
Nurses play a role in providing health information and knowledge. Knowledge is an influential factor in the daily care of tuberculosis patients in undergoing treatment, because with good knowledge, patients will understand their physical condition and are expected to be 
able to carry out good self-care to maintain their health and understand their current condition. Professional nurses have a role to provide support to be able to

(Neves et al., 2019) Design: Descriptive "Social support and study quality of life of people Sample: 57 participant with tuberculosis/HIV" Analysis: Descriptive and inferential statistics

Design: cross sectional study Sample: 50 Participant Analysis: descriptive analysis with Spearman rho test increase the confidence of tuberculosis patients and adherence to treatment and reduce negative consequences such as negative perceptions that will make tuberculosis patients feel insecure and stressed, which will directly impact the quality of life and adherence to treatment in tuberculosis patients

The role of nurses as health

(Munali, Kusnanto, Hanik Endang Nihayati, Hidayat Arifin, 2019)

"The Correlation of Family Support and Health Worker Support with Medication Adherence of TB Patients in Public Health Service Taman" workers is to provide support in the form of health information and provide emotional support that will help patients cope with stress. with the support provided by the nurse is expected to influence the patient's positive actions in undergoing treatment. in addition, nurses also play a role in providing information and working with the patient's family in monitoring taking medication

Other impacts of contracting (Matakanye et al., 2019) Design: Qualitative, "Caring for Tuberculosis exploratory, and Patients: Understanding descriptive the Plight of Nurses at a Sample: 10 participants Regional Hospital" Analysis: Colaizzi's method tuberculosis include the quality of nursing care, fear, anxiety, stress, and the risk of contracting infection, the nurse's perception of the patient, the support structures available in the hospital, and the need for support for nurses

\begin{tabular}{|c|c|c|}
\hline $\begin{array}{l}\text { (Musiimenta et al., } \\
\text { 2020) } \\
\text { "Mobile Health } \\
\text { Technologies May Be } \\
\text { Acceptable Tools for } \\
\text { Providing Social Support } \\
\text { to Tuberculosis Patients } \\
\text { in Rural Uganda" }\end{array}$ & $\begin{array}{l}\text { Design: parallel mixed- } \\
\text { method study } \\
\text { Sample: } 34 \text { participant } \\
\text { Analysis: inductive } \\
\text { content analysis }\end{array}$ & $\begin{array}{l}\text { TB patients receive a variety of } \\
\text { different forms of social support, } \\
\text { including instrumental support, } \\
\text { emotional support, and } \\
\text { informational support via cell } \\
\text { phone. Participants felt that the } \\
\text { SMS notification could motivate } \\
\text { treatment compliance by creating } \\
\text { a sense of personal obligation to } \\
\text { take medication regularly. }\end{array}$ \\
\hline
\end{tabular}




\section{DISCUSSION}

Based on table 1 of the review journal, it is It was found that nurses played a role in social support for tuberculosis, namely in providing a sense of comfort, confidence, enthusiasm for treatment, and eliminating negative thoughts about tuberculosis. (Adu et al., 2020; Garfein and Doshi, 2019). Research conducted by (Arifin et al., 2019) found that nurses have a role including providing empathy, care, and attention given by nurses as treatment supervisors for tuberculosis patients. including expressions of empathy, care, and attention given by the nurse as treatment supervisor for tuberculosis patients . In addition, according to research conducted in the Philippines social support and positive emotional perceptions, given by nurses to patients who are undergoing TB treatment can affect patient compliance in undergoing tuberculosis treatment (Baniqued et al., 2020). in addition nurse plays a role in giving Educating patients, administering medication, communicating with patients, observing and following up on treatment (Carlsson et al., 2019). According to research conducted in Uganda, the use of smartphones as a communication medium provides different social support, namely by providing emotional support, instrumental support, and information via smartphones, besides notifications on smartphones can provide motivation in treatment adherence by creating a sense of obligation to tuberculosis patients to drink. medicine regularly and on time (Musiimenta et al., 2020). In addition to providing support in the form of health information and providing emotional support that will help patients cope with stress, nurses also have a role in providing information and working with the patient's family to monitor taking medication (Munali, Kusnanto, Hanik Endang Nihayati, Hidayat Arifin, 2019).

\section{Sosial Support}

There are five aspects of support included in the social support to tuberculosis patients, namely:

a. Emotional support, this emotional support includes caring, empathy, and attention given by health workers, family, friends, and the community to tuberculosis sufferers (Adu et al., 2020).

b. Award support, appreciation support in the form of expressions of respect for others, encouragement to move forward with positive ideas, and comparisons with other tuberculosis sufferers (Lima et al., 2019).

c. Instrumental support, instrumental support in the form of incentive assistance such as: providing money loans to tuberculosis sufferers. This incentive assistance also includes health insurance provided by the government for tuberculosis sufferers (Ehrlich et al., 2020; Watthananukul et al., 2020).

d. Information support, information support in the form of health information provided by health workers to tuberculosis patients. The role of health workers, especially nurses is very important in providing social support, in this case, is informative support because this is very important in improving the quality of life of tuberculosis patients such as in providing advice and encouragement to carry out routine and regular treatment through therapeutic communication so that it can help patients adapt to stress, overcome psychological disorders, and learn how to relate to other people.(Fadare et al., 2020; Solikhah et al., 2019; Temoteo et al., 2019).

e. Network support, network support, where tuberculosis patients become part of the tuberculosis treatment group to provide motivation and remind each other to 
carry out regular treatment, besides that, health workers regularly monitor patients who are undergoing tuberculosis treatment (Chen et al., 2020; Warsi et al., 2019).

\section{CONCLUTION}

Nurses have a very important role in assisting tuberculosis patients when carrying out treatment, namely providing motivation, empathy, caring, and playing a role in providing health information to tuberculosis patients and their families so that they can jointly accompany treatment and supervise patients so that they take their medication on time regularly until the treatment is complete.

\section{References}

1. Adu PA, Yassi A, Ehrlich R, Spiegel JM. Perceived health system barriers to tuberculosis control among health workers in South Africa. Ann Glob Heal 2020;86:1-10. https://doi.org/10.5334/aogh.2692.

2. Ainiyah SN, Soedarsono S, Umiastuti P. The Relationship between Family's Assessment Support and MDR TB Patient's Adherence on Treatment in RSUD Dr. Soetomo Surabaya. JUXTA J Ilm Mhs Kedokt Univ Airlangga 2019;10:75. https://doi.org/10.20473/juxta.v10i22019.75-78.

3. Arifin VN, Juariah, Nur A, Uzair FM. The Relationship of Social Support with Medication Adherence Pulmonary Tuberculosis Patients Through DOTS Strategy in Pidie Aceh Indonesia. IOP Conf Ser Mater Sci Eng 2019;469. https://doi.org/10.1088/1757-899X/469/1/012055.

4. Baniqued MG, Ballecer BAP, Ballesteros BDC, Balmonte JRR, Bancud EMF, Rebueno MCDR, et al. Social support from nurses and non-adherence with directly observed therapy (DOTS) maintenance phase among patients with tuberculosis in Metro Manila, Philippines. Public Health Nurs 2020;37:339-46. https://doi.org/10.1111/phn.12714.

5. Browne SH, Umlauf A, Tucker AJ, Low J, Moser K, Garcia JG, et al. Wirelessly observed therapy compared to directly observed therapy to confirm and support tuberculosis treatment adherence: A randomized controlled trial. PLoS Med 2019;16:1-19. https://doi.org/10.1371/journal.pmed.1002891.

6. Carlsson M, Johansson S, Eale R-PB, Kaboru BB. Nurses' Roles and Experiences with Enhancing Adherence to Tuberculosis Treatment among 
Patients in Burundi: A Qualitative Study. Tuberc Res Treat 2019;2019:1-9. https://doi.org/10.1155/2014/984218.

7. Chen X, Du L, Wu R, Xu J, Ji H, Zhang Y, et al. The effects of family, society and national policy support on treatment adherence among newly diagnosed tuberculosis patients: a cross-sectional study 2020:1-11. https://doi.org/10.21203/rs.3.rs-25273/v1.

8. Christof C, Nußbaumer-Streit B, Gartlehner G. WHO Guidelines on Tuberculosis Infection Prevention and Control. vol. 82. 2020. https://doi.org/10.1055/a-1241-4321.

9. Cox SN, Elf JL, Lokhande R, Ogale YP, DiAndreth L, Dupuis E, et al. Mobile phone access and comfort: implications for HIV and tuberculosis care in India and South Africa. Int J Tuberc Lung Dis 2019;23:865-72. https://doi.org/10.5588/ijtld.18.0542.

10. Ehrlich R, Spiegel JM, Adu P, Yassi A. Current guidelines for protecting health workers from occupational tuberculosis are necessary, but not sufficient: Towards a comprehensive occupational health approach. Int J Environ Res Public Health 2020;17:1-11. https://doi.org/10.3390/ijerph17113957.

11. Fadare RI, Akpor OA, Ifechukwude IG, Richard D A, Bello CB. Nurses' Safety in Caring for Tuberculosis Patients at a Teaching Hospital in South West Nigeria. J Environ Public Health 2020;2020. https://doi.org/10.1155/2020/3402527.

12. Garfein RS, Doshi RP. Synchronous and asynchronous video observed therapy (VOT) for tuberculosis treatment adherence monitoring and support. J Clin Tuberc Other Mycobact Dis 2019;17:100098. https://doi.org/10.1016/j.jctube.2019.1000988

13. Kumar AA, De Costa A, Das A, Srinivasa GA, D'souza G, Rodrigues R. Mobile health for tuberculosis management in South India: Is video-based directly observed treatment an acceptable alternative? JMIR MHealth UHealth 2019;7. https://doi.org/10.2196/11687. 
14. Lima V, Pellison F, Bernardi F, Carvalho I, Rijo R, Alves D. Proposal of an integrated decision support system for Tuberculosis based on Semantic Web. Procedia Comput Sci 2019;164:552-8. https://doi.org/10.1016/j.procs.2019.12.219.

15. Matakanye H, Ramathuba DU, Tugli AK. Caring for tuberculosis patients: Understanding the plight of nurses at a regional hospital in Limpopo Province, South Africa. Int J Environ Res Public Health 2019;16. https://doi.org/10.3390/ijerph16244977.

16. Munali, Kusnanto, Hanik Endang Nihayati, Hidayat Arifin ROP. CRITICAL MEDICAL AND SURGICAL NURSING JOURNAL ( Jurnal Keperawatan Medikal Bedah dan Kritis ). J Keperawatan Med Bedah Dan Krit 2019;8:8.

17. Musiimenta A, Tumuhimbise W, Atukunda EC, Mugaba AT, Muzoora C, Armstrong-Hough M, et al. Mobile Health Technologies May Be Acceptable Tools for Providing Social Support to Tuberculosis Patients in Rural Uganda: A Parallel Mixed-Method Study. Tuberc Res Treat 2020;2020:1-8. https://doi.org/10.1155/2020/7401045.

18. Neves LA de S, Castrighini CDC, Reis RK, Rita S, Canini S, Gir E. Social support and quality of life of people with tuberculosis / HIV Suporte social e qualidade de vida de indivíduos com coinfecção tuberculose / HIV. Rev Electron Trimest Enferm 2019:21-9.

19. Nezenega ZS, Perimal-lewis L, Maeder AJ. Factors influencing patient adherence to tuberculosis treatment in ethiopia: A literature review. Int J Environ Res Public Health 2020;17:1-12. https://doi.org/10.3390/ijerph17155626.

20. Organization WH. Consolidated Guidelines on Tuberculosis Treatment. 2019.

21. Sekandi JN, Onuoha NA, Buregyeya E, Zalwango S, Kaggwa PE, Nakkonde D, et al. Using a mobile health intervention (DOT selfie) with transfer of social bundle incentives to increase treatment adherence in tuberculosis patients in Uganda: Protocol for a randomized controlled trial. JMIR Res Protoc 2021;10. https://doi.org/10.2196/18029. 
22. Solikhah MM atus, Nursasi AY, Wiarsih W. The relationship between family's informational support and self-efficacy of pulmonary tuberculosis client. Enferm Clin 2019:4. https://doi.org/10.1016/j.enfcli.2019.04.062.

23. Sukartini T, Hidayati L, Khoirunisa N. Knowledge, Family and Social Support, Self Efficacy and Self-Care Behaviour in Pulmonary Tuberculosis Patients. J Keperawatan Soedirman 2019;14.

https://doi.org/10.20884/1.jks.2019.14.2.1011.

24. Temoteo RC de A, Carvalho JBL de, Lira ALB de C, Lima MA de, Sousa YG de. Nursing in adherence to treatment of tuberculosis and health technologies in the context of primary care. Esc Anna Nery 2019;23:1-6. https://doi.org/10.1590/2177-9465-ean-2018-0321.

25. Warsi S, Elsey H, Boeckmann M, Noor M, Khan A, Barua D, et al. Using behaviour change theory to train health workers on tobacco cessation support for tuberculosis patients: A mixed-methods study in Bangladesh, Nepal and Pakistan. BMC Health Serv Res 2019;19:1-14. https://doi.org/10.1186/s12913019-3909-4.

26. Watermeyer J, Penn C. Community perspectives on tuberculosis care in rural South Africa. Heal Soc Care Community 2019;27:182-90. https://doi.org/10.1111/hsc.12637.

27. Watthananukul T, Liabsuetrakul T, Pungrassami P, Chongsuvivatwong V. Effect of Global Fund financial support for patients with multidrug-resistant tuberculosis. Int J Tuberc Lung Dis 2020;24:686-93. https://doi.org/10.5588/ijtld.19.0353. 